\title{
Familial partial 7q monosomy resulting from segregation of an insertional chromosome rearrangement
}

\author{
KAREN BRØNDUM NIELSEN, F. EGEDE, INGELISE MOURIDSEN, \\ AND J. MOHR \\ From the Department of Medical Genetics, The John F. Kennedy Institute, Glostrup; Paediatric \\ Department, Nastved Hospital; Institution for the Mentally Retarded, 'Andersvange', Slagelse; \\ and Institute of Human Genetics, University of Copenhagen, Denmark
}

SUMMARY A family with an insertional type of chromosome rearrangement involving chromosomes 7 and 13 is reported. An interstitial deletion of a segment of chromosome $7(7 q 32 \rightarrow 34)$ had been inserted into the long arm of chromosome 13 at breakpoint q32. Segregation of this chromosome rearrangement gave rise to three subjects who were monosomic for the involved segment of chromosome 7. The karyotypes were: 46,XX, or XY,der(7)ins(13;7) (q32;q32q34). All three subjects were mentally retarded and had minor dysmorphic features. The Kidd, Colton, and Kell blood group syst $\epsilon \mathrm{ms}$ were investigated, but were not informative.

Sixteen case reports describing patients with partial deletion of the long arm of chromosome 7 have been published. Of these, eight were believed to be interstitial deletions (Ayraud et al., 1976; Higginson et al. 1976; Valentine and Sergovich, 1977; Franceschini et al., 1978; Seabright and Lewis, 1978), and the remaining cases were presumably terminal deletions (de Grouchy et al., 1968; Bass et al., 1973; Shokeir et al., 1973; Dinno et al., 1977; Harris et al., 1977a; Kousseff et al., 1977). In four cases (Bass et al., 1973; Shokeir et al., 1973; de Grouchy and Turleau, 1974; Franceschini et al., 1978) the deletions were associated with translocations involving chromosome 7.

We describe a family in which the interstitial deletion of a segment of the long arm of chromosome 7 and its insertion into the long arm of chromosome 13 segregated in three generations. Three related children inherited the derivative 7 chromosome and were consequently monosomic for part of the long arm of chromosome 7. All three children were mentally retarded. The family was ascertained through one retarded child who showed minor dysmorphic features. Fig. 1 shows the pedigree of the family.

Patients and relatives were tested for the Colton and Kidd blood group systems because of the probable location of these systems on chromosome 7

Received for publication 28 March 1979

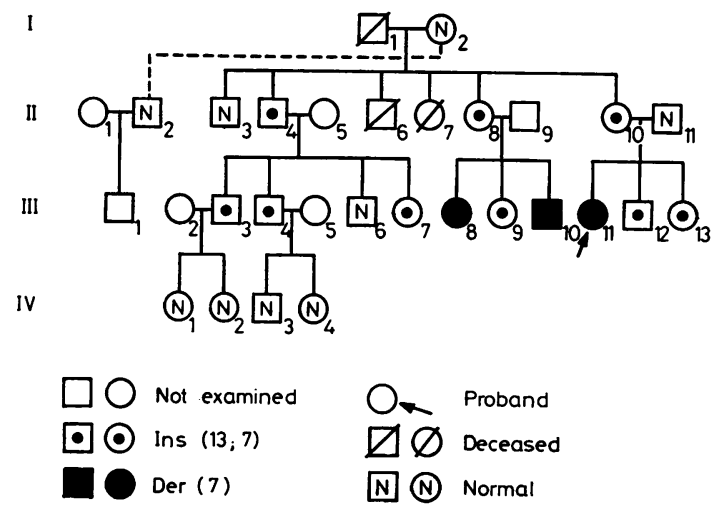

Fig. 1 Pedigree of family.

(Mohr and Eiberg, 1977), and for the Kell system because of an indication of synteny of this system with the Kidd groups (Lewis et al., 1977, personal communication).

\section{Case reports}

III.11, the proband (see Fig. 2), was the first child of healthy parents, and was born at term. No history of spontaneous abortions was reported. The pregnancy 
was complicated by vaginal bleeding for 10 days during the first trimester and crural oedema in the third trimester. Delivery was normal, birthweight $2900 \mathrm{~g}$, length $50 \mathrm{~cm}$. Apgar score was 6 after $1 \mathrm{~min}$, 10 after $5 \mathrm{~min}$. In the neonatal period attacks of cyanosis and twitching of the extremities were observed. Development was retarded, she sat at 10 months of age, walked alone at 28 months, and spoke her first words at 3 years of age. In early childhood she had repeated infections of the middle ear. At 6 years old she was admitted to hospital for recurrent urinary tract infections. Radiography showed a calculus in the left ureter, as well as a large calculus in the left renal pelvis, both of which were removed by surgery. The calculi appeared to contain carbonate, phosphate, and ammonium by chemical analysis. Psychological examination at the age of 6 years showed mild mental retardation. Physical examination showed height and weight within normal limits for age. The face was slightly dysmorphic with hypertelorism, a flat nasal bridge with a broad bulbous tip, a broad, slightly receding chin, and a wide mouth. The ears were low-set. The hands and feet and external genitalia were normal, and neurological examination showed nothing abnormal.

III.8, a maternal first cousin of the proband (Fig. 3), was the first child of healthy parents. Pregnancy and delivery at term were uncomplicated. Birthweight was $2800 \mathrm{~g}$, length $48 \mathrm{~cm}$. During the first year feeding difficulties and failure to thrive were noted. She was treated successfully for mild talipes equinovarus. Development was retarded, she sat at 8 months, walked alone at 24 months, and spoke her first words at 5 years of age. From the age of 7 she has had seizures. At the age of 8, ophthalmological examination revealed bilateral optic atrophy and hypermetropia.

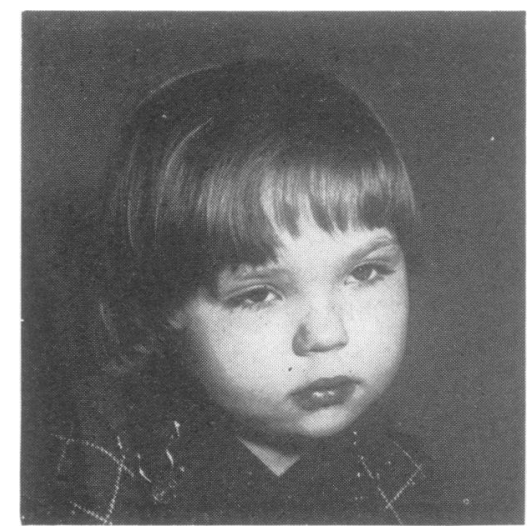

Fig. 2 Proband (III.11) at age 6 years.

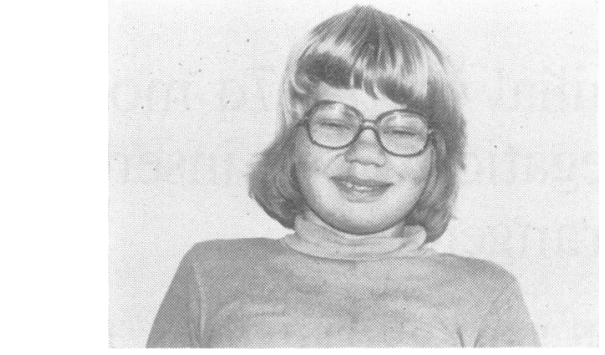

Fig. 3 III.8, first cousin of proband, at age $13 \frac{1}{2}$ years.

Physical examination at the age of $13 \frac{1}{2}$ showed $\stackrel{\text { s. }}{5}$ her to be $30 \mathrm{~cm}$ below the mean for her age. She hado a slight columnar scoliosis and a slightly peculiar facies with a bulbous nose, hypertelorism, and ais large mouth. The ears appeared a little posteriorly rotated. Psychological examination showed develop- ment corresponding to moderate mental retardation.

III.10, brother of III.8 (Fig. 4), was born after an uncomplicated pregnancy 3 weeks after term.尺्ठ Delivery was normal, birthweight $3450 \mathrm{~g}$, length 523 $\mathrm{cm}$. He thrived poorly in the neonatal period ando proved allergic to cow's milk. At one year old he was admitted to hospital for fever, convulsions, åd urinary tract infection. Urography was norma1. Developmental milestones were delayed, he sat 10 months, walked at 24 months, and spoke Fs first words at 25 months. Physical examination ato 6 years of age showed normal height and weight:ٌ Neurological examination showed slight spasticity of: the legs. The face was slightly dysmorphic with slight hypertelorism, mild synophrys, bulbous nose, and 3 large mouth. The ears appeared large and wello modulated. Psychological examination showedô. severe retardation.

Table 1 summarises the clinical findings in eighto previously reported patients with distal or termina?. deletions of the long arm of chromosome 7 comparedo

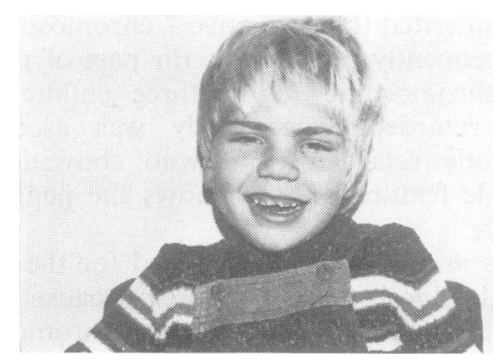

Fig. 4 III.10, brother of III.8, at age 6 years. 
Table 1 Clinical characteristics in 8 patients* with terminal deletions of chromosome 7 with breakpoint $7 q 32$ compared to present cases

\begin{tabular}{|c|c|c|c|c|}
\hline \multirow{2}{*}{$\begin{array}{l}\text { Previous cases } \\
(4 \text { male, } 4 \text { female })\end{array}$} & \multirow{2}{*}{$\begin{array}{l}\text { Positivel } \\
\text { informative }\end{array}$} & \multicolumn{3}{|c|}{ Present cases } \\
\hline & & III.11 & III.8 & III. 10 \\
\hline \multicolumn{5}{|l|}{ Low birthweight } \\
\hline $\begin{array}{c}(52500 \mathrm{~g}) \\
\text { Microcephaly }\end{array}$ & $4 / 7$ & $\overline{-}$ & 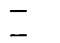 & $\overline{-}$ \\
\hline $\begin{array}{l}\text { Microcephaly } \\
\text { Mental retardation }\end{array}$ & $\begin{array}{l}7 / 7 \\
7 / 7\end{array}$ & $\bar{t}$ & $\bar{t}$ & $\bar{t}$ \\
\hline \multicolumn{5}{|l|}{ Postnatal growth } \\
\hline retardation & $7 / 7$ & - & + & - \\
\hline \multicolumn{5}{|l|}{ Hypertelorism/broad } \\
\hline nasal bridge & $5 / 7$ & + & + & + \\
\hline Bulbous nasal tip & $5 / 7$ & + & + & + \\
\hline Large mouth & $3 / 6$ & + & + & + \\
\hline Cleft lip/palate & $3 / 8$ & - & - & - \\
\hline Large ears & $4 / 6$ & - & - & + \\
\hline Abnormal genitalia & $5 / 8$ & - & - & - \\
\hline Abnormal palmar creases & $5 / 8$ & - & - & - \\
\hline
\end{tabular}

*Shokeir et al. (1973), de Grouchy and Turleau (1974), Harris et al. (1977a, b), Kousseff et al. (1977), Biederman and Bowen (1978).

with the present cases. All were associated with breakpoint $\mathrm{q} 32$ and loss of some or all bands more distally.

\section{CYTOGENETIC INVESTIGATIONS}

Lymphocyte cultures from the proband and members of the family were studied with the aid of QFQbanding (Paris Conference, 1971; Supplement, 1975). One abnormal chromosome 7 with apparent terminal deletion of the long arm was found in the proband. Further investigation employing Gbanding by buffer using Giemsa (GBG-banding), and R-banding by BUdR using acridine orange (RBA-banding) in the proband and her mother showed the mother to be a balanced carrier of a direct insertion into chromosome 13 at breakpoint q32 of a segment of chromosome 7 (q32q34). The deletion of chromosome 7 thus appeared to be interstitial, with preservation of the most distal bands, although the possibility that the deletion was in fact larger with distal breakpoint at q36 could not be entirely excluded. The mother's karyotype was: $46, X X$,ins $(13 ; 7)$ (q32;q32q34). The proband inherited the deleted chromosome 7 and is monosomic for the segment 7q32q34. Her karyotype was: $46, X X$,der(7)ins(13;7) (q32;q32q34)mat.

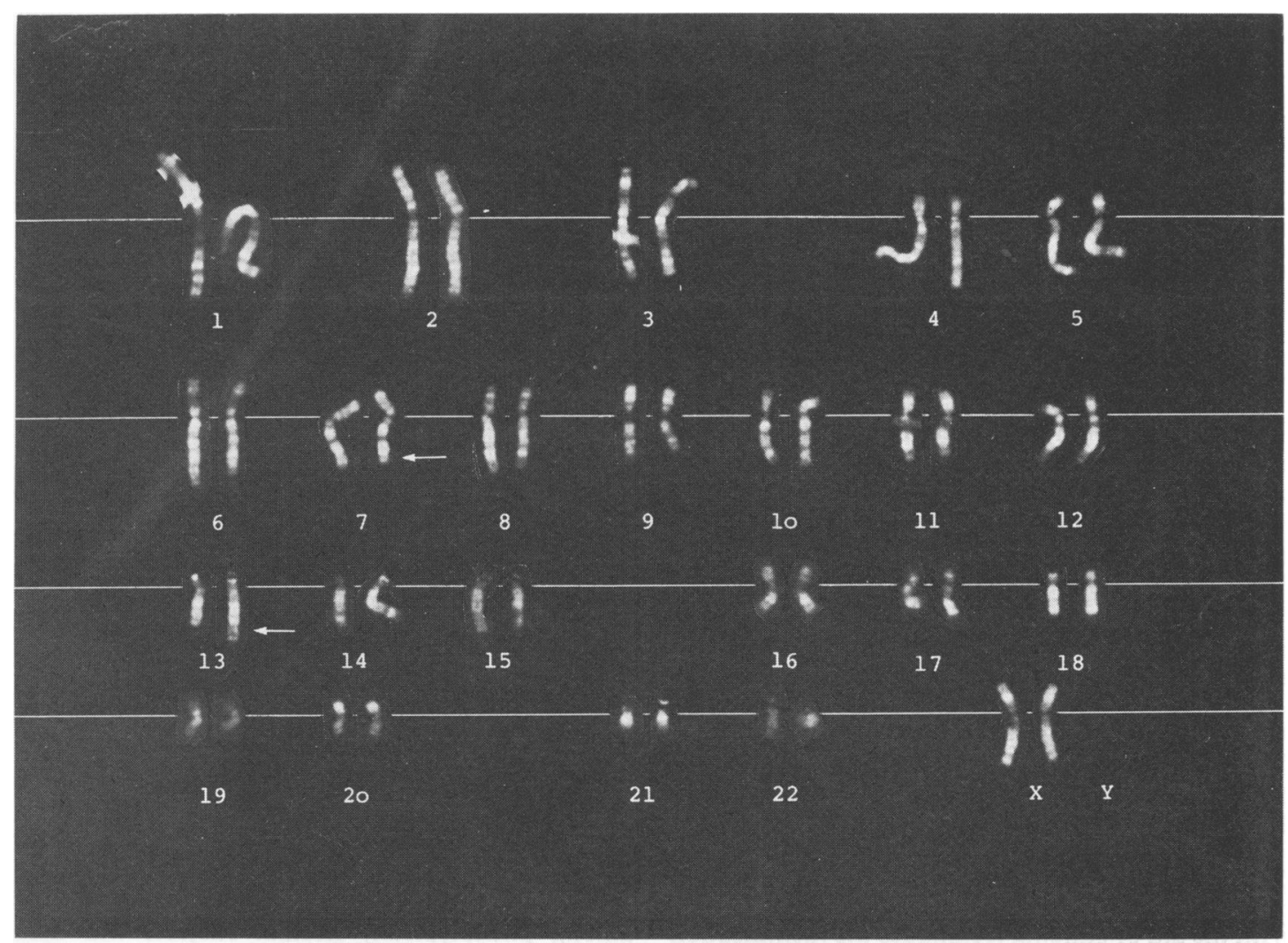

Fig. 5 Karyotype of proband's mother, 46,XX,ins $(13 ; 7)(q 32 ; q 32 q 34)$. Arrows indicate deleted chromosome 7 and additional bands on chromosome 13 (Q-banding). 


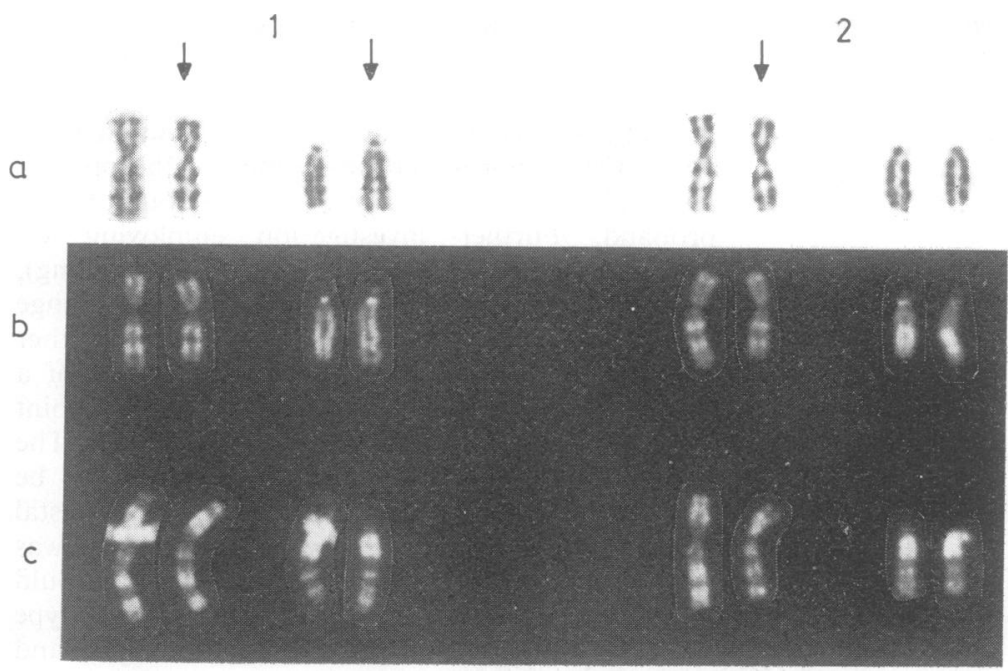

Fig. 6 Partial karyotypes from balanced carrier (1) and probatad (2), showing rearrangement of $\mathrm{c}$ chromosomes 7 and 13 in balancerd carrier, and derivative chromosomte 7 in proband. (a) G-banding, (b) Q-banding, (c) R-banding. Arrows point to abnormal chromosomes.

Table 2 Blood group investigations

\begin{tabular}{|c|c|c|c|c|c|}
\hline & \multicolumn{2}{|c|}{ Colton } & \multicolumn{2}{|c|}{ Kidd (Jk) } & \multirow{2}{*}{$\frac{\text { Kell }}{K}$} \\
\hline & $a$ & $b$ & $a$ & $b$ & \\
\hline I. 2 & + & - & + & + & - \\
\hline II. 2 & + & - & - & + & - \\
\hline II. 3 & + & - & - & + & - \\
\hline II.4 & + & - & + & - & - \\
\hline II. 8 & + & + & + & + & - \\
\hline II.9 & + & - & + & + & - \\
\hline II. 10 & + & - & + & + & - \\
\hline II.11 & + & - & + & + & - \\
\hline III.3 & + & + & + & + & - \\
\hline III.4 & + & + & + & - & - \\
\hline III.6 & + & - & + & - & - \\
\hline III.7 & + & + & + & + & - \\
\hline III.10 & + & - & - & + & - \\
\hline III.11 & + & - & - & + & - \\
\hline
\end{tabular}

A karyotype from a balanced translocation carrier, as well as partial karyotypes from the proband and carrier, are shown in Figs. 5 and 6.

Family investigations showed nine members of the family in three generations to be balanced carriers. Three children were monosomic for the segment $7 \mathrm{q} 32 \mathrm{q} 34$ (the proband and her two maternal first cousins). Three people were dead before the investigation.

\section{BLOOD GROUP INVESTIGATIONS}

The results of the Kidd, Colton, and Kell blood groups are given in Table 2. Fourteen members of the family were available for examination.

\section{Discussion}

With the aid of banding techniques the identification of insertional translocations in man have become possible and a number of case reports have appeared in recent years (Rethoré et al., 1972; Shapiro a\&d Warburton, 1972; Chudley et al., 1974; Francesch?i et al., 1978; Toomey et al., 1978).

Insertional translocations may result in partial trisomies or partial monosomies in the offspsirifg. One previous report describing partial monosingy $7 \mathrm{q}$ resulting from an insertional translocation has appeared (Franceschini et al., 1978). In our rề the chromosome rearrangement was found fo segregate in three generations in a large famidy, causing monosomy for the segment $7 \mathrm{q} 32 \mathrm{q} 34$ gn three members. It is of interest to note that according to the family report two sibs of the probanes mother (II.6 and II.7) died in the neonatal period. They may have had unbalanced karyotypes.

A segregation analysis of this family showed apparent difference between the segregation pattegegn in the offspring of carrier mothers and those iof carrier fathers. (The proband's maternal grandfather, I.1, as well as II.6 and II.7, are excluded from this analysis as they were dead before the investigation. I.1, however, was presumably a translocation carrier.) Two female carriers thus produced among them three karyotypically unbalanced children amd three translocation carriers, whereas three carrièr fathers (II.4, III.3, and III.4) produced eight phenotypically normal children, three of whom wore carriers.

The risk of monosomy $7 \mathrm{q}$ in offspring of carrier mothers seems to be high $(2 / 5$, excluding the proband). The proportion of translocation carriers among phenotypically normal subjects was 8/4 which was not significantly different from the expected value of $0 \cdot 5$. 
The 7q monosomy karyotype probably arose from a segregational event which resulted in equal numbers of gametes carrying either the derivative chromosome 7 along with the normal 13, or the derivative chromosome 13 with the normal 7. Fertilisation of the latter gamete would result in offspring trisomic for the segment 7q32q34, but this was not observed in this family. In the unlikely event of crossing over within the interstitial segment, even more unbalanced karyotypes might result. None of the retarded children in our report showed remarkable major or minor malformations that initially led the clinicians to suspect a chromosomal syndrome. Nevertheless, their facies showed some peculiarities. In a comparison of five $7 \mathrm{q}-$ subjects Harris et al. (1977b) suggested a dysmorphological syndrome associated with a terminal deletion of chromosome 7 . The breakpoint in all five cases was found to be identical to the breakpoint in our patients. The facies of these patients seem to resemble our three patients.

A review of published reports showed a total of eight previous cases with distal deletion associated with breakpoint $7 \mathrm{q} 32$ and loss of bands $\mathrm{q} 32 \rightarrow \mathrm{qter}$. We found a comparison of clinical features relevant, though the amount of chromosomal loss may be larger than in our patients.

However, many of the reported features were apparently also present in the group of patients with interstitial deletions of bands proximal to $7 \mathrm{q} 32$, as has been pointed out by Biederman and Bowen (1978). More refined banding methods with better resolution might help in identifying with greater precision the bands involved in the deletions.

The genetic marker studies were not informative as to the location of the investigated gene systems. Neither of the two patients (III.10 and III.11) tested for blood groups showed any deviation from the normal expression of the Colton, Kidd, or Kell systems. As shown by de la Chapelle et al. (1975), the Colton system is not expressed at all in certain leukaemia patients with monosomy 7 in their bone marrow, and non-expression of the system in the two patients could conceivably have suggested its location in the deletion region, although nonexpression in the leukaemia patients is admittedly not so far understood.

The segregation in the kindred of the chromosomal abnormalities and of the three marker systems did not carry significant information either. In family II. 4 and II. 5 the carrier parent was homozygous for all the three marker systems, and in each of the two remaining matings of generation II only one child was examined for markers, namely the proband III.11 and her maternal first cousin III.10.

We thank Mrs Hanne Poulsen and Mrs Birthe
Jespersen for expert technical assistance and $\mathrm{Dr}$ Margareta Mikkelsen for valuable discussions concerning the manuscript.

\section{References}

Ayraud, N., Rovinski, J., Lambert, J. C., and Galiana, A. (1976). Deletion interstitielle du bras long d'un chromosome 7 chez une enfant lepréchaune. Annales de Génétique, 19, 265-267.

Bass, H. N., Crandall, B. F., and Marcy, S. M. (1973). Two different chromosome abnormalities resulting from a translocation carrier father. Journal of Pediatrics, 83, 1034-1038.

Biederman, B., and Bowen, P. (1978). Balanced $t(8 ; 9)$ (q12;p33)pat carrier with phenotypic abnormalities attributable to a de novo terminal deletion of the long arm of chromosome 7. Human Genetics, 41, 101-107.

Chapelle, A. de la, Vuopio, P., Sanger, R., and Teesdale, Ph. (1975). Monosomy 7 and the Colton blood groups. Lancet, $2,817$.

Chudley, A. E., Bauder, F., Ray, M., McAlpine, P. J., Pena, S. D. J., and Hamerton, J. L. (1974). Familial mental retardation in a family with an inherited chromosome rearrangement. Journal of Medical Genetics, 11, 353-363.

Dinno N., Fu-sun Yen, Podruch, P., and Weisskopf, B. (1977). A case report of 46,XY,del (7) (q23). Birth Defects: Original Article Series, 13, 3c, 228-229.

Franceschini, P., Silengo, M. C., Davi, G. F., Santoro, M. A., Prandi, G., and Fabris, C. (1978). Interstitial deletion of the long arm of chromosome $746, X X$,del (7) (pter $\rightarrow$ q2200::q3200 $\rightarrow$ qter). Human Genetics, 44, 345-348.

de Grouchy, J., and Turleau, C. (1974). Tentative localization of a Hageman (factor XII) locus on 7q, probably the 7q35 band. Humangenetik, 24, 197-200.

de Grouchy, J., Veslot, J., Bonette, J., and Roidot, M. (1968). A case of $26 \mathrm{p}$ - chromosomal aberration. American Journal of Diseases of Children, 115, 93-99.

Harris, E. L., Wappner, R. S., and Palmer, C. G. (1977a). 7q deletion syndrome? Birth Defects: Original Article Series, 13, 3b, 244.

Harris, E. L., Wappner, R. S., Palmer, C. G., Hall, B., Dinno, N., Seashore, M. R., and Breg, W. R. (1977b). 7q deletion syndrome (7q32 $\rightarrow$ 7qter). Clinical Genetics, 12, 233-238.

Higginson, G., Weaver, R., Magenis, E., Prescott, G., Haag, C., and Hepburn, D. J. (1976). Interstitial deletion of the long arm of chromosome no. $7(7 q-)$ in an infant with multiple anomalies. Clinical Genetics, 10, 307-312.

Kousseff, B. G., Hsu, L. Y. F., Paciuc, S., and Hirschhorn, K. (1977). A partial long arm deletion of chromosome 7: 46,XY, del (7) (q32). Journal of Medical Genetics, 14, 144-147.

Mohr, J., and Eiberg, H. (1977). Colton blood groups: indication of linkage with the Kidd (Jk) system as support for assignment to chromosome 7. Clinical Genetics, 11, 372-374.

Paris Conference (1971) Supplement (1975). Standardization in human cytogenetics. Birth Defects: Original Article Series, 11, No. 9, 1975. The National Foundation-March of Dimes, New York.

Rethoré, M-O., Lejeune, J., Carpentier, S., Prieur, M., Dutrillaux, B., Seringe, Ph., Rossier, A., and Job, J-C. (1972). Trisomie pour la partie distale du bras court du chromosome 3 chez trois germains. Premier example d'insertion chromosomique: ins(7;3) (q31;p21 p26). Annales de Génétique, 15, 159-165. 
Seabright, M., and Lewis, G. M. (1978). Interstitial deletion of chromosome 7 detected in three unrelated patients. Human Genetics, 42, 223-226.

Shapiro, L. R., and Warburton, D. (1972). Interstitial translocation in man. Lancet, 2, 712-713.

Shokeir, M. H. K., Ying, K. L., and Pabello, P. (1973). Deletion of the long arm of chromosome no. 7: tentative assignment of the Kidd (Jk) locus. Clinical Genetics, 4, 360-368.

Toomey, K. E., Mohandas, T., Sparkes, R. S., Kaback, M. M., and Rimoin, D. L. (1978). Segregation of an insertional chromosome rearrangement in three generations. Journad of Medical Genetics, 15, 382-387.

Valentine H., and Sergovich, F. (1977). A syndromథ associated with interstitial deletion of chromosome $7 \mathrm{q}$. Birth Defects: Original Article Series, 13, 3b, 261-267.

Requests for reprints to Dr K. B. Nielsen, Depart ment of Medical Genetics, The John F. Kenned Institute, 7 Gl. Landevej, DK 2600 Glostrup Denmark. 